\title{
Formulation and Evaluation of Dolutegravir Proliposomal Powder for Pediatric HIV Patients
}

\author{
Naseeb Basha Shaik' ${ }^{1}$ Divya Shakelli', Lakshmi PK ${ }^{1 *}$, Basava Rao VV² \\ 'Department of Pharmaceutics, G. Pulla Reddy College of Pharmacy, Osmania University, Hyderabad, Telangana, INDIA. \\ 2Department of Pharmacy, University College of Technology, Osmania University, Hyderabad, Telangana, INDIA.
}

\begin{abstract}
Objectives: The objective of the present study was to improve the absorption of dolutegravir sodium by developing oral proliposomal formulation. Methods: Proliposomal formulations were prepared by film deposition on carrier method using cholesterol along with various lipids and different carriers. Three factors (independent variables) such as different lipids (X1), different carriers (X2) and different ratio of lipid: cholesterol (X3) were studied at all three levels, while \% entrapment efficiency (\%EE) (Y) was taken as the response (dependent variable). The proliposomes were optimized by Taguchi OA (L9) experimental design using Minitab 18 English software. Results and Discussion: Proliposomes were evaluated and the $\%$ EE of optimized proliposomal formulation (PL7) found to be $84.02 \%$. In vitro drug release was performed in $0.1 \mathrm{~N} \mathrm{HCl}$ and in $6.8 \mathrm{pH}$ phosphate buffer with SLS using USP type II dissolution apparatus, the \% drug release found to be $12.71 \%$ in $120 \mathrm{~min}$. and $98.95 \%$ in $80 \mathrm{~min}$. respectively, which indicates the drug is not released in acidic medium. Surface morphology was coarse, non-porous and irregular in shape, hydration is rapid and complete conversion of proliposomes to liposomes vesicles within 2-3 $\mathrm{min}$. The mean particle size is $276.6 \mathrm{~nm}$, polydispersity index is 0.329
\end{abstract}

and zeta potential is $-9.54 \mathrm{mV}$, may prevent aggregation of vesicles and formulation is stable. Ex-vivo absorption studies were done using the rat non-everted intestinal sac model, permeation studies revealed that $P_{\text {app }}$ of the optimized proliposomal formulation and IR tablet found to be 1.19 and $0.995 \mathrm{~cm} / \mathrm{sec}$ respectively indicates enhanced absorption than the pure IR tablet. Conclusion: The proliposomal formulation indicated a stable formulation with significant improvement in absorption of dolutegravir sodium.

Key words: Bioavailability, Proliposomes, Dolutegravir, HIV, Thin film hydration, Entrapment efficiency and Taguchi design.

\section{Correspondence}

\section{Dr. PK Lakshmi}

Professor, Department of Pharmaceutics, G. Pulla Reddy College of Pharmacy, Mehdipatnam, Hyderabad-500028, Telangana, INDIA.

Phone no: +919000044452

Email: drlakshmisuresh@gmail.com

DOI: 10.5330/ijpi.2020.4.83

\section{INTRODUCTION}

The oral route of administration is the most preferred route because of its high patient compliance and ease in dosing. However, drugs administered through oral route may result in variable therapeutic response and poor bioavailability because of the drug's poor solubility, insufficient permeation, degradation of drug in gastric environment, poor permeation through permucosal clearance and extensive first-pass metabolism. There are various reasons for increasing interest in lipidbased systems like liposomes to improve the bioavailability. Liposomes are vesicular systems, which are colloidal, concentric bilayered vesicles where aqueous compartment is completely enclosed by a bilayer membrane, mainly composed of natural or synthetic phospholipids/ lipids. However, liposomes are reasonably unstable colloidal system manifested by physical and chemical instability. Physical instability is due to vesicle aggregation and fusion, which is because of changes in vesicle size and loss of entrapped material. Chemical instability due to hydrolysis of the ester bonds linking the fatty acids to the glycerol backbone and peroxidation of unsaturated acyl chains (if present) which accelerates liposome breakdown and alters drug-release characteristics. ${ }^{1}$ Many approaches have been developed to overcome the problems, some of which include, changing the lipid composition, control of particle size and lamellarity, lyophilisation, electrosteric stabilization etc. Proliposome (PL) is one of such approach to overcome the stability issue related with liposome.

Proliposomes (PLs) are dry, free-flowing granular products composed of drug and phospholipids, on addition of water, powder will disperse to form a multi-lamellar liposomal suspension. This is one of the simple and extensively used method to produce commercial liposome products. Due to intrinsic property, proliposomes on contact with water, it forms hydrated membrane lipids for formation of vesicles. It is based upon the intrinsic property. ${ }^{2}$

Dolutegravir sodium is a second-generation HIV integrase strand transfer inhibitor (INSTI) and it belongs to BCS class II drug, indicating that it is a poorly soluble and a highly permeable drug, formulated proliposomes to enhance the oral bioavailability of the drug using lipids and carriers. ${ }^{3-6}$

\section{MATERIALS AND METHODS}

\section{Materials}

Dolutegravir sodium gift sample was obtained from Ikon Bio Pharma Ltd., Mumbai, India; Distearoyl-phosphatidyl choline (DSPC) and Dipalmitoyl phosphatidyl choline (DPPC) were gift samples from VAV Lipids Pvt. Ltd., Mumbai, India; Phospholipon $90 \mathrm{H}$ was procured from Lipoid AG, Germany; Cholesterol, chloroform and ethanol was procured from Yarrow Chemicals Pvt. Ltd., Mumbai, India; Spray dried mannitol, Maltodextrin, Galen-IQ were gifted by Signet Chemical Corporation Pvt. Ltd., Mumbai, India; All other chemicals and reagents used were of analytical grade. 


\section{Preparation of Proliposomal powder}

Proliposomes were prepared by film deposition on carrier method using cholesterol along with various lipids like DSPC, DPPC, Phospholipon $90 \mathrm{H}$ and different carriers such as maltodextrin and co-processed excipients such as Pearlitol SD 200 and Galen-IQ. In this method, accurately weighed amounts of the lipids, cholesterol and drug are dissolved in $10 \mathrm{ml}$ of chloroform and ethanol (8:2) to form a evaporative mixture and then a water soluble carrier is added to the solution. The organic solvent mixture is then subjected to evaporation to make sure the solvent is completely removed via rotary flash evaporator (SUPERFIT/ SUPERVAC) at $60^{\circ} \mathrm{C}$ temperature at $100 \mathrm{rpm}$ for about $1 \mathrm{hr}$. After the complete drying of the solvent, ensure that the resultant proliposomal powder form is further keep overnight in vacuum to remove the traces of solvent. The proliposomal formulations were then passed through the sieve \# 60 mesh; $300 \mu \mathrm{m}$ to get free flowing powder. Then the proliposomal powder fill into glass vials and refrigerate to store at $4^{\circ} \mathrm{C}$ for further characterization. ${ }^{7-10}$

\section{Optimization of the proliposomal formulation using Taguchi OA L9 design experiment}

Taguchi L9 orthogonal array was used for choosing the best and optimized proliposomal formulation using the Minitab 18 English software. The experimental runs were conducted varying three factors of three different levels at a time using Taguchi $\mathrm{L}^{9}$ orthogonal array $\left(3^{3}\right)$ design of experiment depicted in Table 1. Three factors (independent variables) such as different lipids, different carriers and different ratio of lipid: cholesterol were studied at all three levels. Percentage entrapment efficiency was taken as the response (dependent variable). The resultant formulations were studied for percentage yield, flow properties, entrapment efficiency. Table 2 indicates Taguchi $\mathrm{L}^{9}$ OA experimental design runs formula PL1 to PL9 for preparation of proliposomes by film deposition on carrier method.

\section{Design of experiment for choosing the best and optimized formulation}

\section{Preformulation Studies}

\section{Analytical Methodology}

To detect the drug for drug content, \% encapsulation efficiency, in vitro drug release and ex-vivo permeation samples was done by UV spectrophotometric method was used by using an UV-Visible double spectrophotometer (Chemito 2600 double beam spectrophotometer). For in vitro in $0.1 \mathrm{~N} \mathrm{HCl}, 6.8 \mathrm{pH}$ phosphate buffer with SLS and for ex vivo Krebs-Henseleit solution were used.

\section{Drug excipients compatibility studies}

To check compatibility of drug and excipients, studied by Fourier Transform Infra-Red (FTIR) Spectroscopy.

Table 1: Taguchi L9 orthogonal array $\left(3^{3}\right)$ design of experiment.

\begin{tabular}{cccc}
\hline $\begin{array}{c}\text { Factors } \\
\text { (Independent } \\
\text { variables) }\end{array}$ & Level 1 & Level 2 & Level 3 \\
\hline Factor A & 90 H and DSPC & 90 H nad DPPC & DSPC \\
Factor B & Mannitol & Maltodextrin & Galen-IQ \\
Factor C & $1: 1$ & $0.5: 0.5$ & $1.5: 1.5$ \\
\hline
\end{tabular}

Note: $90 \mathrm{H}=$ Phospholipon 90H; Factor A: Types of lipids; Factor B: Types of carriers; Factor C: Ratio of lipid: cholesterol.

\section{Characterization and evaluation for optimization of proliposomal powder of dolutegravir sodium}

Film deposition on carrier method was used to prepare total 9 formulations (PL1 to PL9). The prepared proliposomal formulation physical appearance, \% yield, \% EE, drug content, flow properties, hydration study and number of vesicles per cubic meter etc.

\section{Flow properties}

The proliposomal powders flow properties of were determined mainly by angle of repose, Carr's compressibility index and Hausner's ratio. To determine angle of repose, fixed funnel method was used. The bulk and tapped density of the proliposomal powders were used to calculate Carr's compressibility index and Hausner's ratio. ${ }^{10}$

\section{Vesicles per cubic meter}

Proliposomal powder was hydrated with water for the formation of liposomal vesicles. Proliposomal dispersion (without sonication) and the number of liposomes per cubic mm were counted by optical microscopy by haemocytometer. The liposomes in 80 small squares were counted and calculated by using the following formula:

$$
\begin{gathered}
\begin{array}{c}
\text { Total no.of liposomes counted } \\
\times \text { dilution factor } \times 4000
\end{array} \\
\text { Total no.of squares counted }
\end{gathered}
$$

\section{Microscopic examination}

For microscopic examination samples were prepared by addition of a drop or small amount of distilled water to the proliposomes powder on a glass slide without the cover slip and observed the proliposomes by using an optical microscope at 1000x.

\section{Hydration study}

Proliposomes prepared by the above carrier deposition method were hydrated with the required amount of distilled water. A weighed quantity of $30 \mathrm{mg}$ proliposomal powder was vortex mixed for $2 \mathrm{~min}$. To ensure complete solution/dissolution of the carrier particles and hydration/ dispersion of the lipid. Heating and then gently cooling of hydrated liposomes is performed by leaving the liposomes without shaking or disruption at a temperature above the phase transition of the lipid mixture used. This may help overcome possible structural defects of the liposome bilayers following lipid phase hydration. ${ }^{11,12}$

\section{$\%$ Entrapment efficiency}

Entrapment Efficiency is determined by using an ultracentrifuge. In this dolutegravir sodium loaded proliposomal powder was reconstituted with $6.8 \mathrm{pH}$ phosphate buffer, then transferred into Eppendorf tubes. Free dolutegravir sodium was separated from the dolutegravir sodium loaded liposomes by centrifugation at $6000 \mathrm{rpm}$ for $30 \mathrm{~min}$., whereas the dolutegravir sodium loaded liposomes will settle at the bottom. Then supernatant containing the free dolutegravir sodium was diluted and analyzed in UV visible spectrophotometer. ${ }^{11,12}$ The $\%$ EE calculated by the formula

Total amount of drug-amount of drug

$$
\text { detected in supernatant }
$$

$\% \mathrm{EE} \frac{\text { Total amount drug added }}{2} \times 10$

\section{Drug content}

$100 \mathrm{mg}$ of proliposomes formulation were dissolved in $10 \mathrm{ml}$ methanol and sonicated for about $10 \mathrm{~min}$. using bath sonicator. The clear solution after suitable dilution with $6.8 \mathrm{pH}$ phosphate buffer solution, then filter by 
whatman filter paper. Filtrate was measured by U.V spectrophotometer against blank at $\lambda_{\max } 260 \mathrm{~nm}$ and the drug content was calculated. ${ }^{11,12}$

Drug content $=\frac{\text { Weight of drug in the proliposomes }}{\text { Total Weight of the proliposomes powder }}$ X 100

\section{Surface morphology by SEM}

Scanning electron microscopy (SEM) was determined to study the surface morphology of proliposomes. Proliposomes powder is sprinkled uniformly on aluminium microscopy stubs. The surface was gold-coated with a sputter coater. Surface morphology of the samples was examined using a scanning electron microscope and samples were photographed using the instrument's software. ${ }^{13}$

\section{Particle size and Zeta potential determination}

The prepared proliposomes vesicle size was determined by hydration of the proliposomal formulations by using purified water at $25^{\circ} \mathrm{C}$ under sonication for $30 \mathrm{~min}$. using a bath sonicator. The average particle size, PDI and zeta potential were measured at $25^{\circ} \mathrm{C}$ using the dynamic light scattering technique by using Malvern Zeta-sizer. ${ }^{13}$

\section{In vitro drug release studies}

The in vitro drug release studies were conducted in USP Type II dissolution apparatus for the optimized proliposomal formulation. The paddle speed was set at $50 \mathrm{rpm}$ and the media temperature was adjusted to $37 \pm 0.2^{\circ} \mathrm{C} .900 \mathrm{ml}$ of the dissolution medium used $0.1 \mathrm{~N} \mathrm{HCl}$ and $6.8 \mathrm{pH}$ phosphate buffer for IR tablet and proliposomal formulation equivalent to $37 \mathrm{mg}$ of dolutegravir filled in a dialysis bag and tied to the paddle. Samples were collected at predetermined time intervals up to $120 \mathrm{~min}$. in $0.1 \mathrm{~N} \mathrm{HCl}$ and $90 \mathrm{~min}$. in $6.8 \mathrm{pH}$ phosphate buffer. Samples were collected at predetermined time points, collected samples were filtered using a $0.45 \mu \mathrm{m}$ Whatman filter paper and analyzed in UV Visible spectrophotometer. The percentage of drug release from the formulation was estimated. In order to understand the barrier effect of the dialysis membrane, dissolution experiments were carried out in triplicate. Calculate the percentage of drug release from the formulations. ${ }^{14}$

\section{Model dependent kinetics of optimized formulations}

The release patterns and mechanisms are described by various other linear and non-linear kinetic models that are dependent on the curve fitting procedure. The dissolution profile of PL7 formulation was subjected to Zero-order, First-order, Higuchi diffusion and Korsemayerpeppas diffusion models to find out the kinetic modelling of drug release.

\section{Ex vivo intestinal absorption studies}

Ex vivo studies performed using rat intestine after getting the approval from the Institutional Animal Ethical Committee (IAEC) and conducted studies in accordance with disciplinary principles and guidelines by the committee for the purpose of control and supervision of experiments on animals (CPCSEA). Male Sprague-Dawley rats weighing about 200 g were taken and euthanized. (320/CPCSEA; Dated 03-01-2001 and ID number GPRCP/IAEC/10/18/02/PCE/AE-I-Rats-M-21; G. Pulla Reddy College of Pharmacy, Mehdipatnam, Hyderabad, India).

\section{Preparation of intestinal sacs and determination of drug transport across the rat intestine}

For determination of drug transport across membrane non-everted intestinal sacs were used. The Male Sprague-Dawley rat animals were housed under normal $12 \mathrm{hr}$ light/ dark cycle and under optimum temperature with excess availability of water. The animals were kept fasted for $8 \mathrm{hr}$ and then sacrificed. To remove the intestine, an insertion was made midline of the abdomen. Isolated intestine was then washed with an ice cold oxygenated Krebs Henseleit solution (KHS). The washed intestine was divided into approximately $10 \mathrm{~cm}$ long sacs. The one end of the sacs was tied using braided suture silk, filled with drug solution from the other end through a blunt syringe and then tied. ${ }^{15-17}$

The sacs were filled with the drug solution $(40 \mu / \mathrm{ml}$ drug in KHS solution) from the other end through a blunt syringe and then tied. The sacs were immersed in $50 \mathrm{ml}$ beaker containing $30 \mathrm{ml}$ Krebs Henseleit solution and it was placed on a magnetic stirrer and a magnetic bead was allowed to rotate at $25 \mathrm{rpm}$ and the temperature was maintained at $37^{\circ} \mathrm{C}$ with adequate aeration. From outside of the sac $4 \mathrm{ml}$ samples were withdrawn for every $1 \mathrm{hr}$ and replaced with fresh physiological solution at different time points. The drug content present in the samples were analyzed using UV-visible spectrophotometer at $264 \mathrm{~nm}$.

Dolutegravir apparent permeability coefficient $\left(\mathrm{P}_{\text {app }}\right)$ was calculated using the equation:

$$
P_{a p p}=(d Q / d t) \times\left(1 / A C_{0}\right)
$$

Where; $\mathrm{P}_{\text {app }}(\mathrm{cm} / \mathrm{sec})$ is the apparent permeability coefficient, $\mathrm{dQ} / \mathrm{dt}(\mu \mathrm{g} /$ $\mathrm{sec}$ ) is the total amount of drug transported across the membrane per unit of time. Plot the graph time versus concentration, calculate the slope of the linear portion of graph and considered as permeation flux. $\mathrm{A}\left(\mathrm{cm}^{2}\right)$ is the intestinal sacs surface area accessible for drug permeation and $\mathbf{C}_{\mathbf{0}}$ $(\mu \mathrm{g} / \mathrm{ml})$ is the initial amount of the drug inside the sacs.

Table 2: Taguchi $L^{9} \mathrm{OA}$ experimental design runs formula for preparation of proliposomes.

\begin{tabular}{cccccccccc}
\hline Material (mg) & PL1 & PL2 & PL3 & PL4 & PL5 & PL6 & PL7 & PL8 & PL9 \\
\hline Dolutegravir sodium & 37 & 37 & 37 & 37 & 37 & 37 & 37 & 37 & 37 \\
Cholesterol & 39 & 19.5 & 58.5 & 19.5 & 58.5 & 39 & 58.5 & 39 & 19.5 \\
$90 \mathrm{H}$ & 39 & 19.5 & 58.5 & 19.5 & 58.5 & 39 & - & - & - \\
DSPC & 39.5 & 19.75 & 59 & - & - & - & 118.5 & 79 & 39.5 \\
DPPC & - & - & - & 18 & 55 & 36.5 & - & - & - \\
Mannitol & 150 & - & - & 150 & - & - & 150 & - & - \\
Maltodextrin & - & 150 & - & - & 150 & - & - & 150 & - \\
Galen-IQ & - & - & 150 & - & - & 150 & - & - & 150 \\
Chloroform: & Up to & & & & & & & & \\
Ethanol (4:1) & $5 \mathrm{ml}$ & & & & & & & & \\
\hline
\end{tabular}

Note: 90H= Phospholipon 90H; DSPC: Di Stearoyl Phosphatidyl Choline; DPPC: Di Palmitoyl Phosphatidyl Choline; mg: milligram, ml: milliliter. 


\section{Stability studies}

Stability studies were carried out for one month by keeping optimized formulations in amber coloured glass containers, they were kept in a desiccator at room temperature and refrigerator $\left(4 \pm 2{ }^{\circ} \mathrm{C}\right)$. At defined time intervals samples were withdrawn and analysed for physical appearance, hydrated to obtain liposomes and \% entrapment efficiency. ${ }^{18}$

\section{RESULTS}

\section{Analytical Methodology}

The analytical method developed for dolutegravir sodium was performed for determination of absorption maxima $\left(\lambda_{\max }\right)$ in $0.1 \mathrm{~N}$ $\mathrm{HCl}$ is $258.8 \mathrm{~nm}$, in $\mathrm{pH} 6.8$ phosphate buffer with SLS is $259.2 \mathrm{~nm}$ and in Krebs Henseleit solution is $264 \mathrm{~nm}$.

\section{Drug excipients compatibility studies by FTIR}

The FTIR peaks identified in the pure drug were relatively same when compared with the optimized formulation spectra, indicating that no drug-excipient interaction i.e. the pure drug was not altered its functional characteristics and it is compatible with excipients.

\section{Optimization of proliposomal powder of dolutegravir sodium using Taguchi OA L9 design experiment Analysis of the results by Taguchi designs}

Taguchi L9 orthogonal array was used for choosing the best and optimized proliposomal formulation using the Minitab 18 English software. The data were plotted on the main effect plots to assess the relationship between the dependent and independent variables. The obtained results (\% entrapment efficiency data) response was analysed. The magnitude of the inter-relationship effect is high as the slope of the line is steeper (Figure 1). It can be concluded that factor a (type of lipid) has more impact on \% entrapment efficiency. Therefore, the order of independent variables on which $\%$ entrapment efficiency depends was type of lipid > type of carrier > ratio of lipid: cholesterol.

Based on Taguchi L9 OA experimental design, film deposition on carrier method was used to prepare total 9 formulations (PL1 to PL9). The prepared proliposomal formulation studied for physical appearance, $\%$ yield, hydration study, \% EE, drug content, flow properties and number of vesicles per cubic meter depicted in Table 3.

\section{Flow properties}

The micrometrics of the proliposome powder formulation plays very important role in handling and production operations because the dose or content uniformity and filling into container is determined by the proliposomal powder flow properties. To evaluate the nature of powder
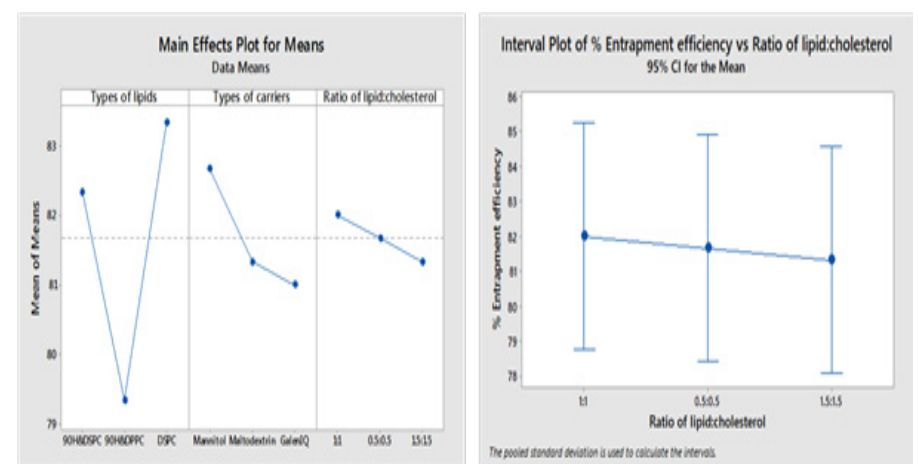

Figure 1: Main effect plot for Means and Interval plot of response Vs ratio of lipid and cholesterol. flow, the angle of repose, Hausner's ratio and Carr's index were measured and the results were depicted in Table 3. The optimised formulation (PL7) flow property values like angle of repose (33.74 \pm 0.14$)$, Carr's index $(11.5 \pm 0.33)$ and Hausner's ratio $(1.11 \pm 0.34)$ were in an acceptable range. The smaller the value of angle of repose, lesser the internal friction or cohesion between the particles and greater the flow characteristics and vice-versa.

\section{Hydration study}

The process of hydration of proliposomes and liposomes formation from proliposomes on contact with water is illustrated in the Figure 2. The results indicate that the process of dissolution or disintegration may happen by hydration of the lipid present in the proliposomes, taking the form of liposomes moving away from the central core of the proliposome until both hydration of the lipid and dissolution of the carrier is complete. The Figure 2 indicates the complete conversion of proliposomes to vesicles took place within 2-3 min of hydration. The rapid alteration of proliposomes to liposomes, which confirmed that on contact with the physiological fluid, proliposomes can be converted into liposomes quickly.

\section{\% Entrapment efficiency}

The effect of different lipids, carriers and varying ratio of lipid:cholesterol on the entrapment efficiency has been studied. The \% entrapment efficiency of the all 9 proliposomal formulations observed between $79 \pm 0.05$ and $84 \pm 0.03$ (Table 3 ). It was observed that there is a variation on the encapsulation efficiency seen with hydrophobic molecules like dolutegravir due to the increasing or decreasing amount of cholesterol. The results indicate that the formulations containing 1:1 ratio of lipid and cholesterol have increased entrapment efficiency when compared to the $0.5: 0.5$ ratio. This might be due to increase in the hydrophobicity of the bilayered membrane which may favour the inclusion of hydrophobic molecules. Upon further increase in the cholesterol and lipid ratio i.e. 1.5:1.5 there was a decrease in the entrapment efficiency, may be attributed due to the decreased space for accommodation of the drug in vesicle. Formulations containing DSPC have higher entrapment efficiency than DPPC with Phospholipon 90H. This lipids effects depends upon the alkyl chain length. Longer the chain length, higher the
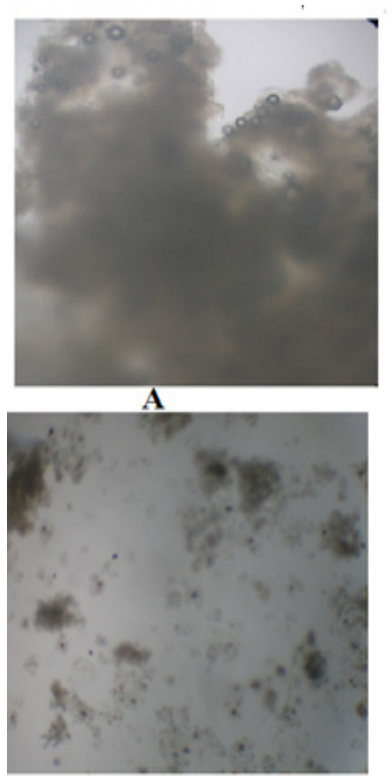

C
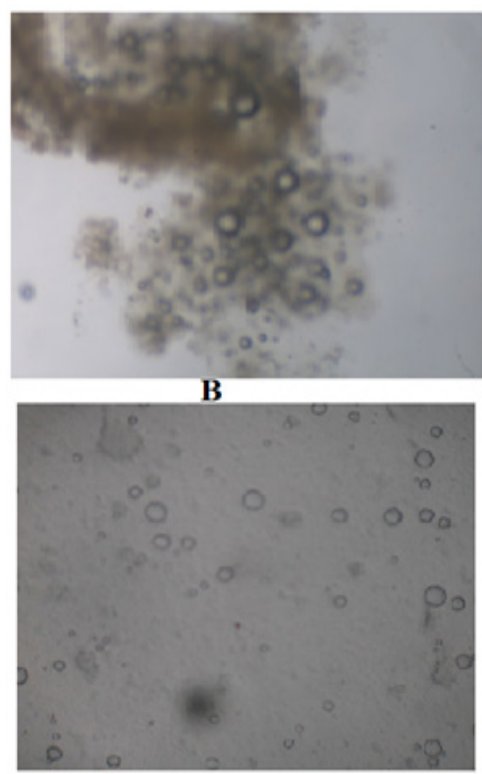

D
Figure 2: Hydration of the optimized formulation (PL7). 
entrapment efficiency and vice versa. DSPC having longer alkyl chain form more rigid lipid membrane owing to Vander Waals forces. ${ }^{18-20}$

\section{Drug content}

The percentage drug content for all the prepared formulations were presented in Table 3. The content of the drug ranged from $89.77 \%$ to 97.33\%. PL2 and PL7 formulations were found to have maximum drug content which indicates that efficient loading into the vesicles and uniform distribution of drug throughout the powder. ${ }^{21,22}$

\section{Surface morphology by SEM}

The surface morphology of the proliposomal powder was done by SEM and is shown in the Figure 3. Mannitol based proliposomal optimized formulation (PL7) surface morphology exhibited was coarse non-porous and irregular in shape.

\section{Particle size and Zeta potential}

The size of the liposomal vesicles generated from proliposome after reconstitution in water. The mean size is $276.6 \mathrm{~nm}$, polydispersity index is 0.329 (Figure 4) and showing vesicles are of uniform size. Zeta potential of the optimized proliposomal formulation (PL7) is $-9.54 \mathrm{mV}$ (Figure 4). Negative value of formulation zeta potential may be due to the negative charge/s of the polar head group present in the phospholipid. This value indicates prevention of aggregation of vesicles..$^{22}$ The value of zeta potential proves the stability of the particulate systems.

\section{In vitro drug release studies}

In vitro drug release studies performed for the optimized proliposomal formulations. To ensure the stability of the liposomes during the passage through the gastrointestinal tract, the leakage of the entrapped dolutegravir sodium from the optimized proliposomal formulations (PL1 and PL7) in comparison to the IR tablet was investigated in vitro, using $0.1 \mathrm{~N} \mathrm{HCl}$ as dissolution media ${ }^{23}$ (Figure 5). The in vitro drug release studies play an important role to know the amount of the drug that has actually diffused across the dialysis membrane over a period of time and thus the \% release of drug from immediate release tablet (IR tablet) and proliposomal formulations were calculated and the drug release from the proliposomal powder was studied to know the influence of the lipids used in the formulation.

PL1 formulation containing DPPC and Phospholipon $90 \mathrm{H}$ released $19.40 \pm 0.14 \%$ in comparison to PL7 formulation released $12.71 \pm 0.15 \%$. Where, IR tablet showed $90.61 \pm 0.06 \%$ of drug release in $0.1 \mathrm{~N} \mathrm{HCl}$ media. As the drug is unstable in acidic $\mathrm{pH}$ and undergoes degradation, the liposomal formulations are preferred to reduce loss of drug due to degradation.

The dissolution profile of proliposomal formulations containing dolutegravir sodium (PL1 and PL7) in $6.8 \mathrm{pH}$ phosphate buffer with SLS is shown in the Figure 6. The percent drug release was comparatively higher for optimized proliposomal formulation (PL7), than PL1 formulation. As DSPC liposomal formulations (PL7) have shown better stability in acidic $\mathrm{pH}$, this was further selected for performing ex-vivo studies.

\section{Model dependent kinetics of optimized formulations}

The optimized proliposomal formulation followed first-order drug release kinetics with the Higuchi drug release mechanism. The value of release component " $n$ " (0.732) indicates anomalous diffusion release mechanism. The release process involves the penetration of water into the powder followed by the dissolution of the carrier, lipid and diffusion of the drug dissolved in the matrix (Table 4).

Table 3: Results of proliposomal formulations.

\begin{tabular}{|c|c|c|c|c|c|c|c|c|c|c|}
\hline $\begin{array}{l}\text { Formulation } \\
\text { Code }\end{array}$ & $\begin{array}{c}\text { Physical } \\
\text { Appearance }\end{array}$ & $\%$ Yield* & $\% \mathrm{EE}^{*}$ & $\begin{array}{c}\text { Drug } \\
\text { content* }\end{array}$ & $\begin{array}{c}\text { Angle of } \\
\text { repose } \\
()^{*}\end{array}$ & $\begin{array}{c}\text { Bulk } \\
\text { density } \\
\left(\mathrm{gm} / \mathrm{cm}^{3}\right)^{*}\end{array}$ & $\begin{array}{c}\text { Tapped } \\
\text { density } \\
\left(\mathrm{gm} / \mathrm{cm}^{3}\right)^{*}\end{array}$ & $\begin{array}{c}\text { Carr's } \\
\text { index } \\
(\%)^{*}\end{array}$ & $\begin{array}{l}\text { Hausners } \\
\text { ratio* }\end{array}$ & $\begin{array}{c}\text { *No. vesicles } \\
\text { per } \\
\mathrm{m}^{3} \times 10^{3}\end{array}$ \\
\hline PL1 & $\begin{array}{l}\text { Non sticky } \\
\text { powder }\end{array}$ & $85 \pm 0.05$ & $84 \pm 0.03$ & $98.31 \pm 0.25$ & $32 \pm 0.12$ & $0.414 \pm 0.19$ & $0.466 \pm 0.36$ & $12.5 \pm 0.23$ & $1.12 \pm 0.16$ & $3.43 \pm 0.03$ \\
\hline PL2 & $\begin{array}{c}\text { Non sticky } \\
\text { powder }\end{array}$ & $83 \pm 0.03$ & $82 \pm 0.05$ & $96.07 \pm 0.27$ & $33 \pm 0.21$ & $0.408 \pm 0.17$ & $0.459 \pm 0.35$ & $12.5 \pm 0.37$ & $1.12 \pm 0.39$ & $3.21 \pm 0.04$ \\
\hline PL3 & Slightly sticky & $93 \pm 0.02$ & $81 \pm 0.06$ & $95.3 \pm 0.94$ & $33 \pm 0.22$ & $0.391 \pm 0.32$ & $0.447 \pm 0.25$ & $14.3 \pm 0.25$ & $1.14 \pm 0.28$ & $3.09 \pm 0.09$ \\
\hline PL4 & Very sticky & $92 \pm 0.04$ & $80 \pm 0.01$ & $97.34 \pm 0.07$ & $38 \pm 0.16$ & $0.408 \pm 0.24$ & $0.473 \pm 0.09$ & $15.9 \pm 0.21$ & $1.15 \pm 0.11$ & $2.89 \pm 0.11$ \\
\hline PL5 & Very sticky & $93 \pm 0.03$ & $79 \pm 0.09$ & $96.47 \pm 0.06$ & $40 \pm 0.32$ & $0.398 \pm 0.02$ & $0.467 \pm 0.13$ & $17.3 \pm 0.32$ & $1.17 \pm 0.21$ & $3.02 \pm 0.03$ \\
\hline PL6 & Very sticky & $86 \pm 0.02$ & $79 \pm 0.05$ & $98.33 \pm 0.04$ & $37 \pm 0.09$ & $0.379 \pm 0.19$ & $0.442 \pm 0.26$ & $16.6 \pm 0.13$ & $1.16 \pm 0.19$ & $2.73 \pm 0.07$ \\
\hline PL7 & $\begin{array}{l}\text { Non sticky } \\
\text { powder }\end{array}$ & $82 \pm 0.02$ & $84 \pm 0.02$ & $98.33 \pm 0.52$ & $33 \pm 0.14$ & $0.389 \pm 0.30$ & $0.434 \pm 0.17$ & $11.5 \pm 0.33$ & $1.11 \pm 0.34$ & $3.32 \pm 0.01$ \\
\hline PL8 & $\begin{array}{l}\text { Non sticky } \\
\text { powder }\end{array}$ & $76 \pm 0.06$ & $83 \pm 0.01$ & $95.8 \pm 0.43$ & $35 \pm 0.11$ & $0.407 \pm 0.23$ & $0.460 \pm 0.13$ & $13.0 \pm 0.19$ & $1.13 \pm 0.37$ & $3.19 \pm 0.08$ \\
\hline PL9 & $\begin{array}{l}\text { Non sticky } \\
\text { powder }\end{array}$ & $70 \pm 0.07$ & $83 \pm 0.04$ & $94 \pm 0.33$ & $34 \pm 0.27$ & $0.423 \pm 0.11$ & $0.486 \pm 0.18$ & $14.8 \pm 0.12$ & $1.14 \pm 0.17$ & $3.16 \pm 0.02$ \\
\hline
\end{tabular}

Note: \% EE= Percentage entrapment efficiency; \% Yield = Percentage yield; ${ }^{*}$ The values are expressed as their mean $\pm \mathrm{SD}, n=3$;

Table 4: In vitro drug release kinetics of optimized formulation.

\begin{tabular}{cccccccc}
\hline Formulation & \multicolumn{9}{c}{$\mathbf{r}^{2}$} & & Zero \\
\cline { 2 - 5 } & order & First-order & Higuchi & $\begin{array}{c}\text { Korsmeyer } \\
\text { Peppas }\end{array}$ & $\mathbf{n}$ & $\begin{array}{c}\text { Drug transport } \\
\text { mechanism }\end{array}$ \\
\hline PL7 & 0.946 & 0.974 & 0.966 & 0.926 & 0.732 & $\begin{array}{c}\text { Anomalous } \\
\text { transport }\end{array}$ \\
\hline
\end{tabular}




\section{Ex-vivo studies - intestinal absorption of dolutegravir}

An ex vivo studies was performed using non-everted rat intestine. The absorption was estimated through the non-everted intestine segment. The drug permeated and the amount of drug was calculated for PL7 proliposomal formulation and IR tablet. The absorption of drug in proliposomal formulation (PL7) was observed to be increased as compared to IR tablet. The apparent permeability coefficient $\left(\mathrm{P}_{\text {app }}\right)$ of the IR tablet and PL7 formulation were $0.995 \pm 0.15$ and $1.19 \pm 0.11$ respectively as shown in Table 5 . Cumulative concentration of drug absorbed, from the proliposomal formation (PL7) in comparison with IR Tablet as shown in Figure 7.

As dolutegravir sodium belongs to class 2, exhibiting high permeability and low aqueous solubility according to the biopharmaceutic classification, enhanced dissolution leading to higher permeation and thereby to an increase in the bioavailability. (a)

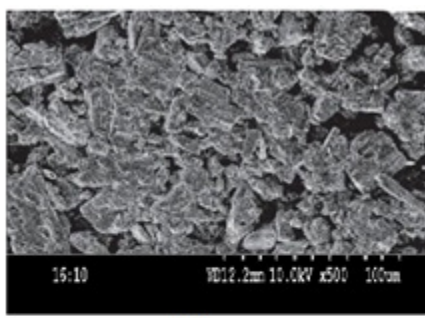

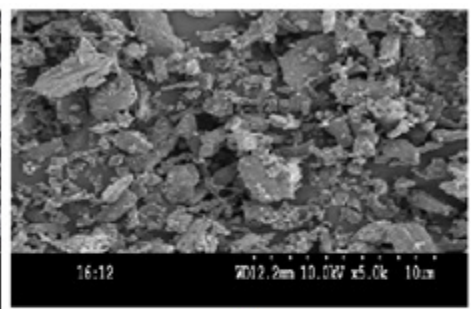

(b)

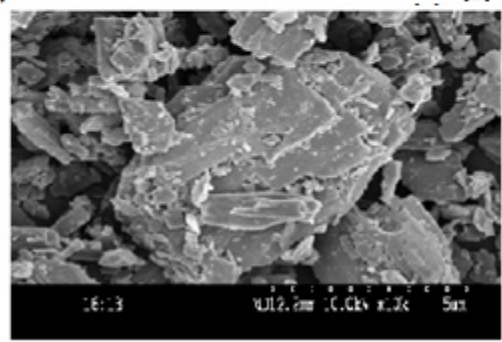

(c)

Figure 3: SEM images of PL7 formulation.

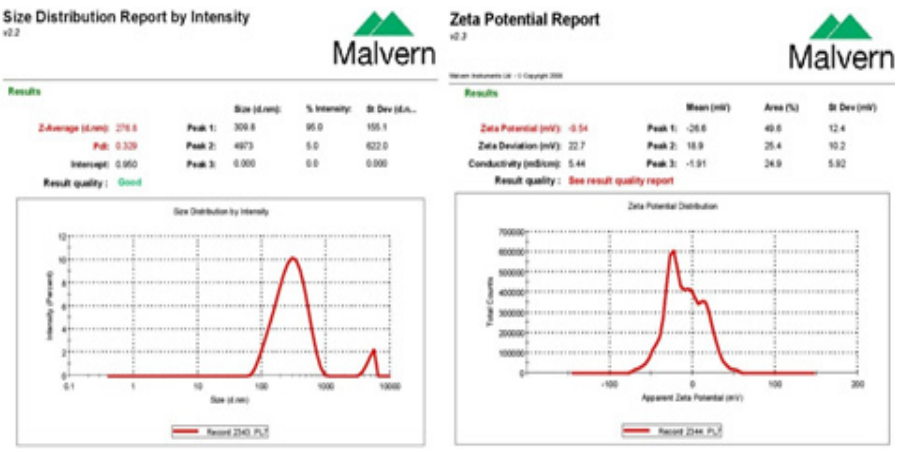

Figure 4: Particle size and Zeta potential of the optimized proliposomal formulation (PL7).

Table 5: Apparent permeability $\left(\mathrm{P}_{\text {app }}\right)$ of dolutegravir sodium through non everted sac.

\begin{tabular}{cc}
\hline Applied solutions & $\mathrm{P}_{\text {app }}(\mathrm{cm} / \mathrm{sec}) \times 10^{-2}$ \\
\hline IR Tablet & $0.995 \pm 0.15$ \\
PL7 formulation & $1.19 \pm 0.11$ \\
\hline
\end{tabular}

Note: The values are expressed as their mean $\pm \mathrm{SD}, n=3$; $\mathrm{cm}$ : centimeter, sec: second.
Studies have shown that proliposomal formulations increased bioavailability and half-life of water insoluble drugs. Thus, proliposomal formulations could be a stable, more bioavailable formulations for poorly soluble drugs..$^{24,25}$

\section{Stability studies}

The stability studies were conducted for one month at room temperature and refrigerator $\left(4 \pm 2^{\circ} \mathrm{C}\right)$. At defined time period, the proliposomal

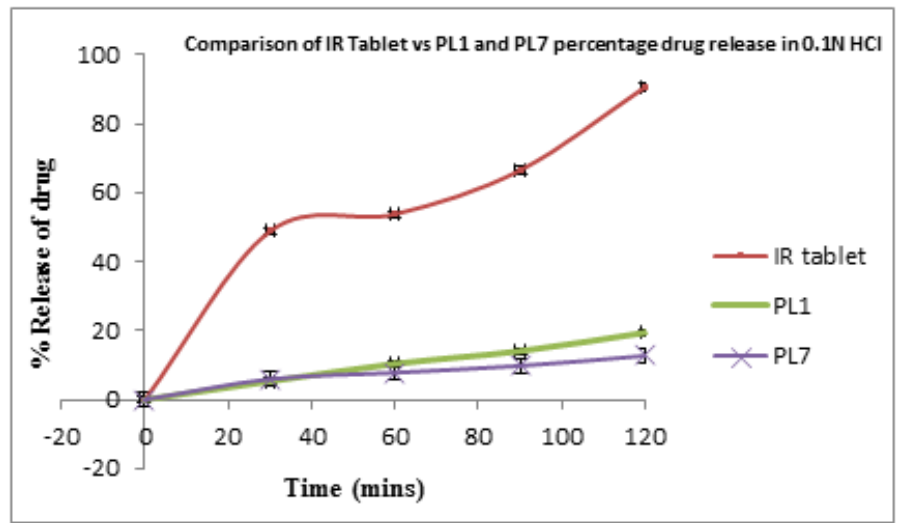

Figure 5: Comparison of IR vs PL1 and PL7 percentage drug release in $0.1 \mathrm{~N}$ $\mathrm{HCl}$.

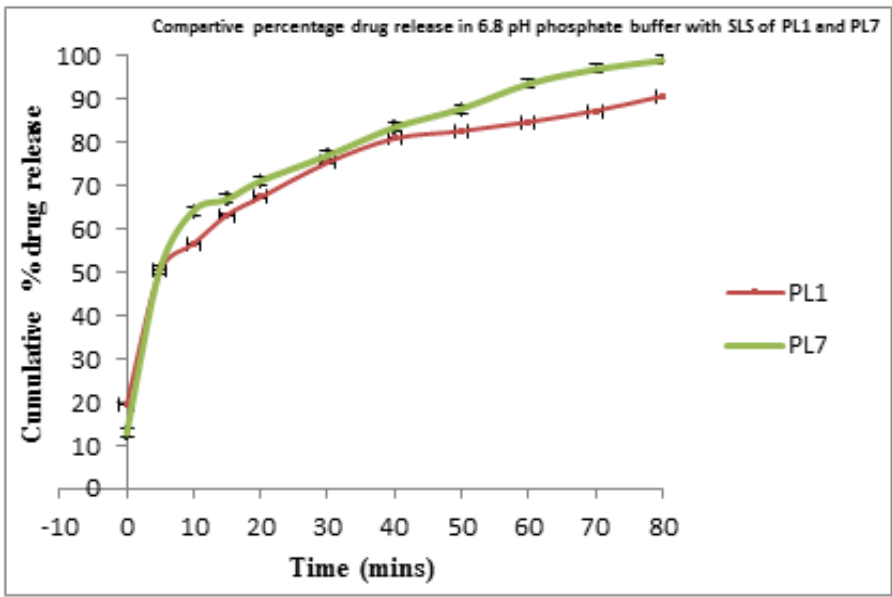

Figure 6: Comparative dissolution profile of PL1 and PL7 in $6.8 \mathrm{pH}$ phosphate buffer with SLS.

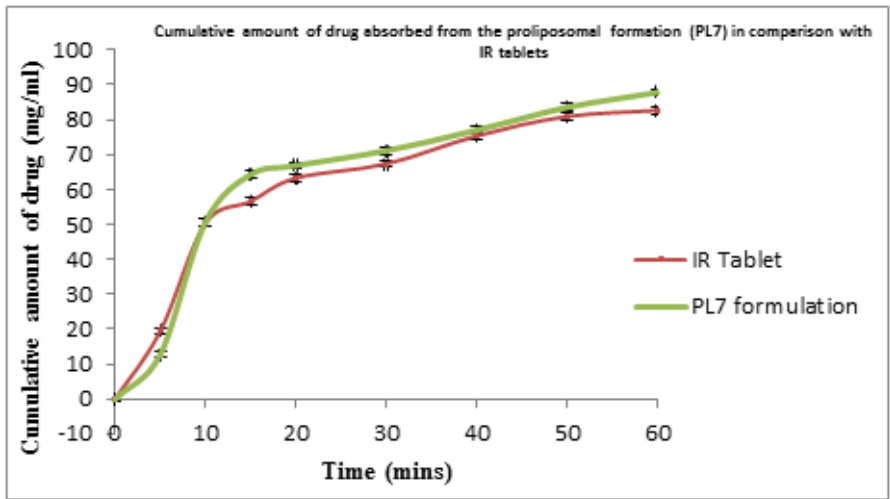

Figure 7: Cumulative concentration of drug absorbed, from the proliposomal formation (PL7) in comparison with IR Tablet. 
formulation was evaluated for entrapment efficiency and hydration study for the formation of liposomes, not much change was observed in the physical appearance and \% encapsulation efficiency which indicates the stability of proliposomal formulation both stored at room temperature and refrigerated temperature.

A stable gastric resistant proliposomes were prepared using synthetic phospholipids and therefore it can be speculated that the proliposomal formulation of dolutegravir sodium will enhance the bioavailability invivo as well.

\section{DISCUSSION}

Proliposomes were successfully prepared using thin film deposition on carrier method. The effect of type of lipid/s, carrier/s and varying ratios of lipid and cholesterol on the entrapment efficiency has been studied. Formulations containing DSPC have higher entrapment efficiency than DPPC with Phospholipon 90H. This lipids effects depends upon the alkyl chain length. Longer the chain length, higher the entrapment efficiency and vice versa. DSPC having longer alkyl chain form more rigid lipid membrane owing to Vander Waals forces. ${ }^{19,20}$

Based on Taguchi L9 orthogonal array it was found that, the magnitude of the inter-relationship effect is high as the slope of the line is steeper (Figure 1), can be concluded that factor A (type of lipid) has more impact on \% entrapment efficiency. Therefore, the order of independent variables on which \% entrapment efficiency depends was type of lipid > type of carrier > ratio of lipid: cholesterol. The prepared proliposomal formulations studied for physical appearance, \% yield, hydration study, $\% \mathrm{EE}$, drug content, flow properties and number of vesicles per cubic meter (Table 3). It can be concluded that good flow properties and the complete conversion of proliposomes to vesicles took place within 2-3 min of hydration (Figure 2), the rapid alteration of proliposomes to liposomes, which confirmed that on contact with the physiological fluid, proliposomes can be converted into liposomes quickly. The $\%$ entrapment efficiency observed between $79 \pm 0.05$ and $84 \pm 0.03$ and \% drug content ranged from 89.77 to 97.33 (Table 3). Based on the entrapment efficiency and flow properties, PL7 was selected as optimized formulation for further study. The in vitro dissolution and diffusion of developed formulation showed less leakage in acidic $\mathrm{pH}$ and drug release profile following first-order kinetics and Higuchi release mechanism. From the values of release component " $n$," it is evident that the formulation has an anomalous diffusion release mechanism. Exvivo studies performed using non-everted rat intestine studies showed significant enhanced drug absorption. As dolutegravir sodium belongs to class 2 , exhibiting high permeability and low aqueous solubility ${ }^{15}$ according to the biopharmaceutical classification system (BCS). Studies have shown that proliposomal formulations increased bioavailability and half-life of water insoluble drugs. Thus, proliposomal formulations of dolutegravir sodium could be a stable, more bioavailable vesicular system. ${ }^{9,23}$ The apparent permeability coefficient $\left(\mathrm{P}_{\text {app }}\right)$ of optimized formulation (PL7) was higher than the IR tablet, which showed an increased oral bioavailability.

\section{CONCLUSION}

Proliposonmal vesicular drug delivery system was prepared in order to prevent acid degradation of the drug and to improve its oral bioavailability by resisting the drug release in the stomach. Dolutegravir Sodium which is having instability in acidic media and low oral bioavailability and successfully formulated as proliposomal vesicular drug delivery system in powder form by film deposition on carrier method. The proliposomal formulations containing cholesterol along with various lipids, different carriers were optimized by Taguchi OA (L9) experimental design. The in vitro dissolution studies and ex-vivo non-everted rat intestine perfusion models showed a considerable enhancement in drug absorption, indicates improved bioavailability of the drug. DSPC lipid was advantageous as it showed minimal leakage of drug in acidic $\mathrm{pH}$, maintaining the integrity of liposomes. In conclusion the bioavailability is enhanced with less leakage of the drug dolutegravir sodium in acidic $\mathrm{pH}$. The potential of proliposomal formulation in enhancing the solubility of the drug dolutegravir sodium is highlighted in this work. Further in-vivo animal studies need to be conducted to prove the bioavailability enhancement of this formulation.

\section{ACKNOWLEDGEMENT}

We thank principal and management of G. Pulla Reddy College of Pharmacy for providing research lab facilities to perform the research studies.

\section{CONFLICT OF INTEREST}

The authors declare no conflict of interest.

\section{REFERENCES}

1. Daeihamed M, Dadashzadeh S, Haeri A, Faghih AM. Potential of liposomes for enhancement of oral drug absorption. Curr Drug Deliv. 2017;14(2):289-303.

2. Payne NI, Timmins P, Ambrose CV, Ward MD, Ridgway F. Proliposomes: A novel solution to an old problem. J Pharm Sci. 1986;75(4):325-9.

3. Blake M, Sonia V. Dolutegravir: A new HIV integrase inhibitor for the treatment of HIV infection. Future Virol. 2014;9(11):967-78.

4. Christopher EK, Sharon L, Walmsely. Dolutegravir- A review of the pharmacology, efficacy and safety in the treatment of HIV. Drug Des Devel Ther. 2015;7(9):3547-55

5. Kalepu S, Nekkanti V. Insoluble drug delivery strategies: Review of recent advances and business prospects. Acta Pharm Sin B. 2015;5(5):442-53.

6. Nekkanti V, Venkatesan N, Betageri GV. Proliposomes for oral delivery: Progress and challenges. Curr Pharm Biotechnol. 2014;16(4):303-12.

7. Velpula A, Jukanti R, Janga KY, Sunkavalli S, Bandari S, Kandadi $P$, et al. Proliposome powders for enhanced intestinal absorption and bioavailability of raloxifene hydrochloride: Effect of surface charge. Drug Dev Ind Pharm. 2013;39(12):1895-906

8. Bobbala SK, Veerareddy PR. Formulation, evaluation and pharmacokinetics of isradipine proliposomes for oral delivery. J Liposome Res. 2012;22(4):285-94. Hiremath PS, Soppimath KS, Betageri GV. Proliposomes of exemestane for improved oral delivery: Formulation and in vitro evaluation using PAMPA, Caco2 and rat intestine. Int J Pharm. 2009;380(1):96-104.

9. Nalla P, Bagam S, Eedara BB, Dhurke R. Formulation and evaluation of domperidone oral proliposomal powders. Int J Pharm Technol Res. 2015;7:10818.

10. Manjula D, Shabaraya AR, Somashekar S. Topical delivery of fenoprofen proliposomes: Preparation evaluation and in vitro release. Int J Pharma Sci Invent. 2014;3(8):6-12

11. Nekkanti V, Rueda J, Wang Z, Betageri GV. Design, characterization and in vivo pharmacokinetics of tacrolimus proliposomes. AAPS Pharm Sci Tech. 2016;17(5):1019-29.

12. Khan I, Yousaf S, Subramanian S, Korale O, Alhnan MA, Ahmed W, et al Proliposomes powder prepared using a slurry method for generation of beclometasone dipropionate liposomes. Int J Pharm. 2015;496(2):342-50.

13. Zheng B, Teng L, Xing G, Bi Y, Yang S, Hao F, et al. Proliposomes containing a bile salt for oral delivery of Ginkgo biloba extract: Formulation optimization, characterization, oral bioavailability and tissue distribution in rats. Eur J Pharm Sci. 2015;77:254-64

14. Amidon GL, Sinko PJ, Fleisher D. Estimating human oral fraction dose absorbed: A correlation using rat intestinal membrane permeability for passive and carriermediated compounds. Pharm Res. 1988;5(10):651-4

15. May SF, Yosra SRE, Ossama YA. Lyophilized phytosomal nanocarriers as platforms for enhanced diosmin delivery: Optimization and ex vivo permeation. Int J Nanomedicine. 2013;8:2385-97.

16. Dixit $P$, Jain DK, Dumbwani J. Standardization of an ex-vivo method for determination of intestinal permeability of drugs using everted rat intestine apparatus. J Pharmacol Toxicol Methods. 2012;65(1):13-7.

17. Hao F, HeY, Sun Y, Zheng B, LiuY, Wang X, et al. Improvement of oral availability of ginseng fruit saponins by a proliposome delivery system containing sodium deoxycholate. Saudi J Biol Sci. 2016;23(1):S113-25.Briuglia ML, Rotella C, McFarlane A, Lamprou DA. Influence of cholesterol on liposome stability and on in vitro drug release. Drug Deliv Transl Res. 2015;5(3):231-42.

18. Anderson M, Omri A. The Effect of Different Lipid Components on the in 
vitro Stability and Release Kinetics of Liposome Formulations. Drug Deli. 2004; 11(1):33-9.

19. Mallesh K, Srinivas C, Nagasree K, Prakash VD. Formulation and evaluation of prednisolone proliposomal gel for effective topical pharmacotherapy. International Journal of Pharmaceutical Sciences and Drug Research. 2012;4(1):35-43.

20. Nekkanti V, Wang Z, Betageri GV. Pharmacokinetic evaluation of improved oral bioavailability of valasartan: Proliposomes versus self-nanoemulsifying drug delivery system. AAPS Pharm Sci Tech. 2016;17(4):851-62.
21. Basalious EB, Shawky N, Badr-Eldin SM. SNEDDS containing bio-enhancers for improvement of dissolution and oral absorption of lacidipine-l: Development and optimization. Int J Pharm. 2010;391(1-2):203-11.

22. Aungst BJ, Saitoh H, Burcham DL, Huang SM, Mousa SA, Hussain MA. Enhancement of the intestinal absorption of peptides and nonpeptides. J Control Release. 1996;41(1):19-31.

23. Harita P, Lakshmi PK. Probilosomes: A Novel bile salt containing nanocarrier for enhancing oral bioavailability. IJPI. 2020;10(1):49-53.

Article History: Submission Date : 11-09-2020; Revised Date : 31-10-2020; Acceptance Date : 01-12-2020.

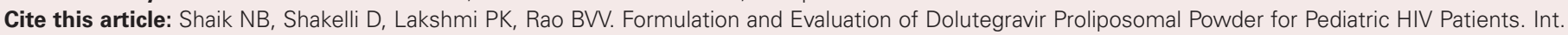
J. Pharm. Investigation, 2020;10(4):471-8. 